\title{
Stabilization of gelatin and carboxymethylcellulose water-in-water emulsion by addition of whey protein
}

\author{
Mayara Rocha Laranjo ${ }^{1}$, Bernardo de Sá Costa ${ }^{2}$ and Edwin Elard Garcia-Rojas ${ }^{1,2 *}$
}

\author{
'Pós-graduação em Engenharia Mecânica - PGMEC, Escola de Engenharia, Universidade Federal \\ Fluminense - UFF, Volta Redonda, RJ, Brasil \\ ${ }^{2}$ Departamento de Engenharia de Agronegócios - VEA, Universidade Federal Fluminense - UFF, \\ Volta Redonda, RJ, Brasil \\ *edwinr@id.uff.br
}

\begin{abstract}
Due to their aqueous nature and biocompatibility, water/water emulsions are particularly advantageous in the production of low calorie functional food and bioactive carrier microparticles. The aim of this study was to investigate the stability of water/water emulsions formed by gelatin and carboxymethycelullose through the Pickering effect, by addition of whey protein particles. The effect of phase composition and $\mathrm{pH}$ on emulsion stability over 3 days of storage was studied and the emulsion properties were characterized. Finally, the effect of the addition of different concentrations of whey protein particles on the emulsion stability was investigated. The added protein particles contributed to reduce the rate of phase separation and higher protein concentration showed this effect more clearly. The time of complete phase separation increased $12 \mathrm{~h}$ after addition of $15 \%(\mathrm{w} / \mathrm{w})$ protein. Emulsions at $\mathrm{pH} 5.5$ with protein particles, however, showed lower stability than those at $\mathrm{pH} 7.5$ without particles.
\end{abstract}

Keywords: biocompatibility, biopolymer, Pickering, phase separation.

How to cite: Laranjo, M. R., Costa, B. S., \& Garcia-Rojas, E. E. (2019). Stabilization of gelatin and carboxymethylcellulose water-in-water emulsion by addition of whey protein. Polimeros: Ciência e Tecnologia, 29(4), e2019051. https://doi. org/10.1590/0104-1428.03319

\section{Introduction}

Kinetically stable water/water (W/W) emulsions have been focus of great interest due to their strategic potential application in cosmetics ${ }^{[1]}$, foods ${ }^{[1-3]}$ and biomedicine ${ }^{[4,5]}$. Originated from an aqueous binary polymeric system, W/W emulsions can be formed by completely biocompatible ingredients, such as proteins and polysaccharides ${ }^{[6]}$, and are ideal for the formulation of fat free food or for the encapsulation of sensitive ingredients, such as cells and proteins ${ }^{[5-9]}$. Several studies on the properties and applications of $\mathrm{W} / \mathrm{W}$ emulsions have been reported in the literature ${ }^{[1-9]}$.

Because W/W emulsions are completely aqueous system, with extremely low interfacial tension and an ill- defined interface, they cannot be stabilized by conventional surfactants, as commonly occurs in water/oil $(\mathrm{W} / \mathrm{O})$ and oil/water $(\mathrm{O} / \mathrm{W})$ emulsions ${ }^{[1-14]}$. One of the notable mechanisms of stabilization is the Pickering method, in which a solid particle added to the system adsorbs at the droplet interface and provides a physical barrier against droplet coalescence ${ }^{[1-14]}$. Recent advances in the research of different substances to adsorb at interfaces between immiscible aqueous solutions have been reliably reported by Dickinson ${ }^{[14]}$. Protein microgels are an example that has already proved to be efficient in stabilizing W/W emulsions ${ }^{[10-12]}$.

In this context, the present study aims to produce and characterize $\mathrm{W} / \mathrm{W}$ emulsions from an aqueous two-phase

system composed of gelatin and carboxymethylcellulose and evaluate the effect of whey protein on kinetic stability.

\section{Materials and Methods}

\subsection{Materials}

Gelatin type B and sodium carboxymethylcellulose (NaCMC) of medium viscosity (400-800 cps), purchased from Sigma Aldrich (Saint Louis, USA), and whey protein isolate (WPI) 90\% (Glanbia Nutritionals, Springfield, United States) were used for the preparation of emulsions. Sodium chloride $(\mathrm{NaCl})$, sodium hydroxide $(\mathrm{NaOH})$, hydrochloric acid $(\mathrm{HCl})$ and sodium azide were purchased from Vetec Química Fina (Duque de Caxias, Brazil). All solutions were prepared in ultrapure water with a conductivity of

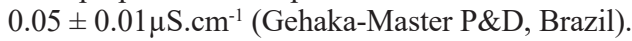

\subsection{Molecular weight determination}

The average viscosity molecular weight of gelatin and $\mathrm{NaCMC}$ was determined by viscometric measurements ${ }^{[15]}$. Samples of gelatin $\left(1-10 \mathrm{gcm}^{-3}\right)$ and $\mathrm{NaCMC}\left(0.4-1.0 \mathrm{~g}^{\mathrm{cm}} \mathrm{cm}^{-3}\right)$ were prepared using aqueous solutions of $\mathrm{NaCl} 0.1 \mathrm{~mol}^{-\mathrm{L}^{-1} \text { as }}$ solvent. The relative viscosity was measured with a capillary (Schott, Cannon Fenske, Germany) in a thermostatic water bath at $25.0 \pm 0.1^{\circ} \mathrm{C}$ (Schott, CT52, Germany). Intrinsic viscosity [ $\eta]$ is defined as (Equation 1): 


$$
[\eta]=\left(\eta_{s p} / C\right)_{C \rightarrow 0}=\left(\eta_{r e d}\right)_{C \rightarrow 0}
$$

The intrinsic viscosity was obtained by extrapolating the reduced viscosity, $\eta_{R E D}$, vs the concentration $(C)$ data to zero concentration. The intercept on the abscissa is the intrinsic viscosity. The average viscosity molecular weight was calculated based on the Mark-Houwink-Sakurada equation (Equation 2):

$$
[\eta]=k M_{v}^{a}
$$

where the constants $k=2.69 \times 10^{-3}$ and $a=0.88$ are defined for gelatin ${ }^{[16]}$ and $k=1.23 \times 10^{-2}$ and $a=0.91$ for $\mathrm{NaCMC}^{[17]}$.

\subsection{Emulsion stability}

\subsubsection{Phase diagram construction}

A phase diagram was constructed by visually observing the formation of two distinct layers and was used to choose the composition of the $\mathrm{W} / \mathrm{W}$ emulsions ${ }^{[18]}$. A stock solution of gelatin $(16 \% \mathrm{w} / \mathrm{w})$ was prepared by diluting the protein in ultrapure water at $60.0 \pm 1.0^{\circ} \mathrm{C}$ under magnetic stirring for $1 \mathrm{~h}$. A stock solution of $\mathrm{NaCMC}(2 \% \mathrm{w} / \mathrm{w})$ was prepared by dilution in ultrapure water at room temperature under magnetic stirring for $12 \mathrm{~h}$. Sodium azide $(0.05 \% \mathrm{w} / \mathrm{w})$ was added to prevent the microbial growth. The $\mathrm{pH}$ was adjusted to 6.0 by the addition of $\mathrm{NaOH}$ or $\mathrm{HCl}$. The stock solutions were diluted to the appropriate ratio in a transparent glass tube and left in a thermostatic water bath (Huber, Germany) at $45.0 \pm 0.1{ }^{\circ} \mathrm{C}$, avoiding any gelation. The mixtures were stirred in a vortex (Phoenix, AP56, Brazil) for $1 \mathrm{~min}$ and stored in a water bath for $48 \mathrm{~h}$ with temperature controlled at $45.0 \pm 0.1{ }^{\circ} \mathrm{C}$.

\subsubsection{Emulsion preparation}

To induce the segregative phase separation (repulsive interactions between the polymers), which is necessary to form $\mathrm{W} / \mathrm{W}$ emulsions ${ }^{[19]}$, the $\mathrm{pH}$ of the stock solutions was adjusted to $5.5,6.5$ or 7.5 . The solutions were placed in a glass tube (11 mm diameter and $150 \mathrm{~mm}$ height) and vortexed (Phoenix, AP56, Brazil) for $1 \mathrm{~min}$. Thereafter, the emulsions were stored in a water bath (Huber, Germany) for $48 \mathrm{~h}$ with temperature controlled at $45.0 \pm 0.1{ }^{\circ} \mathrm{C}$.

\subsubsection{Kinetic stability}

The kinetic stability of the emulsions was evaluated by visually observing the formation of two distinct layers over 3 days of storage ${ }^{[20]}$. The phase separation is expressed by the separation index (SI), which is calculated as the relation between the upper phase volume $(V)$ and the original volume $(V o)$, as described by Equation $3^{[21,22]}$ :

$$
S I=\frac{V}{V_{0}} x 100
$$

\subsection{Emulsion characterization}

The emulsion properties were characterized only for those that remained stable for a period longer than $8 \mathrm{~h}$. All measurements were performed immediately after emulsion preparation.

\subsubsection{Dynamic superficial tension}

The superficial tension of the gelatin and NaCMC aqueous solutions was measured with the pendant drop method using a tensiometer with (Teclis Scientific, Easytrack, France) connected with a thermostatic water bath (Julabo, Corio-CD BC4, Germany) at $45.0 \pm 0.1{ }^{\circ} \mathrm{C}$. To create the air-water interface, a bubble was formed at the end of a needle connected with a syringe and immersed in a glass cuvette filled with a gelatin solution $(6 \%, 8 \%, 10 \%$ and $12 \% \mathrm{w} / \mathrm{w})$ or NaCMC solution $(0.10 \% ; 0.25 \% ; 0.50 \%$ and $1.00 \% \mathrm{w} / \mathrm{w})$. The superficial tension was determined by bubble shape analysis and measured during $1300 \mathrm{~s}$ from bubble formation.

\subsubsection{Particle size and $\zeta$ potential analysis}

The size, size distribution and $\zeta$ potential were determined by laser diffraction using a Zetasizer (Malvern Instruments, Nano ZS90, England). Before the measurement, the emulsions were diluted in ultrapure water at a ratio $1: 10(\mathrm{v} / \mathrm{v})$. The optical properties adopted were refraction index (1.335) and absorption (0.01). The results obtained correspond to the mean and corresponding standard deviation of three replicates.

\subsubsection{Viscosity measurements}

The viscosity of the emulsions was measured by a rotational viscometer (Thermo Fisher Scientific, Haake Viscotester D, Germany) using the LCP spindle at different speeds. The viscosity and percentage of torque were manually recorded when the viscosity reading reached apparent equilibrium. The measurement temperature was controlled at $45.0 \pm 0.5^{\circ} \mathrm{C}$ with a circulating water bath (Quimis, 0214M2, Brazil). The measurements reported correspond to an average of three replicates.

\subsection{Effect of the addition of whey protein isolate on emulsion stability}

The effect of the addition of WPI on emulsion stability was tested on samples that showed poor stability in previously performed tests. The preparation of WPI microgel particles was based on the method of Murray and Phisarnchananan ${ }^{[10]}$. A WPI solution $(10 \% \mathrm{w} / \mathrm{w})$ was prepared by the dispersing the protein in ultrapure water under magnetic stirring for $12 \mathrm{~h}$. The solution was transferred to a glass bottle, heated in a thermostat water bath (Huber, Germany) at $90.0 \pm 1.0^{\circ} \mathrm{C}$ for $30 \mathrm{~min}$ and suddenly cooled under running water for $15 \mathrm{~min}$. The gel formed was roughly broken with a spatula to obtain fine gel fragments which were diluted in water and homogenized by an Ultraturrax system (IKA, T25D, Germany) for $5 \mathrm{~min}$ at $10,000 \mathrm{rpm}$, and again by ultrasound (Hielscher, UP100H, Germany) for 2 min with an amplitude of $100 \%$. The suspension obtained was centrifuged (Digicen 21R, Spain) with the RT504 rotor at 9,000 rpm until the microgel sedimented to leave a clear upper aqueous phase which was carefully removed via a pipette. To prepare the emulsions, different concentrations of the WPI microgel particles $(5,10$ and $15 \% \mathrm{w} / \mathrm{w})$ were added to the aqueous system of gelatin-NaCMC before homogenization in the vortex. The influence of the WPI on emulsion stability was statistically evaluated by application of the analysis of variance (ANOVA) using the software Statistical Analysis System version 9.2 (SAS Institute Inc ${ }^{\circledR}$, Cary, NC). 


\section{Results and Discussion}

\subsection{Molecular weight determination}

The intrinsic viscosity $[\eta]$ and the average viscosity molecular weight $\left(\mathrm{M}_{\mathrm{v}}\right)$ of gelatin and $\mathrm{NaCMC}$ are presented in Table 1 .

In the literature, it is possible to find a wide variety of molecular weight values for gelatin, resulting from a polydisperse protein with broad molecular weight distribution in solution ${ }^{[23]}$. According to Ledward ${ }^{[24]}$, the molecular weight of gelatin type B can vary between 100 and $500 \mathrm{kDa}$. Riihimaki ${ }^{[16]}$ determined the molecular weight of gelatin type $\mathrm{B}$ from different origins using the viscometer method and found values between 45 and $170 \mathrm{kDa}$ and Masuelli ${ }^{[25]}$ found $[\mathrm{n}]=48.65 \mathrm{~cm}^{3} \cdot \mathrm{g}^{-1}$ in a $0.01 \mathrm{~mol} \cdot \mathrm{L}^{-1} \mathrm{NaCl}$ solution and $\mathrm{M}_{\mathrm{v}}=67.44 \mathrm{kDa}$, using the same method.

$\mathrm{NaCMC}$, as well as many other derivative polysaccharides, has a heterogeneous molecular weight distribution and chemical composition, which explain the diversity of molecular weight values found in the literature. Vázquez et al. ${ }^{[26]}$ characterized the average molecular weight of $\mathrm{NaCMC}$ of medium viscosity using a capillary viscometer and found $[\eta]=535 \mathrm{~mL} \cdot \mathrm{g}^{-1}$ and $\mathrm{M}_{\mathrm{v}}=124.94 \mathrm{kDa}$. Sharma et al. ${ }^{[27]}$ determined $[\mathrm{n}]=198 \mathrm{~cm}^{3} \cdot \mathrm{g}^{-1}$ and $\mathrm{M}_{\mathrm{v}}=90 \mathrm{kDa}$ and Gomez-Diáz and $\mathrm{Navaza}^{[28]}$ found $[\mathrm{n}]=643.9 \mathrm{~cm}^{3} \cdot \mathrm{g}^{-1}$ and $\mathrm{M}_{\mathrm{v}}=386 \mathrm{kDa}$. Rinaudo et al. ${ }^{[29]}$ characterized CMC samples by size exclusion chromatography and found molecular weights between 55.83 and $578.58 \mathrm{kDa}$. CMC is highly heterogeneous polymer whose molecular weight depends on the internal structure, mainly the degree of polymerization and the degree of substitution ${ }^{[30]}$.

\subsection{Emulsion stability}

\subsubsection{Phase diagram construction}

Figure 1 shows the visual phase diagram constructed for gelatin and $\mathrm{NaCMC}$ solutions in water at $\mathrm{pH} 6.0$ and $45.0 \pm 0.1{ }^{\circ} \mathrm{C}$. According to the phase diagram, two distinct regions could be visualized: a one-phase region (homogeneous system), corresponding to the area below the binodal line, and a two-phase region (non-homogeneous system), corresponding to the area above the bimodal line. At relatively low gelatin and $\mathrm{NaCMC}$ concentrations the systems formed a single phase. The minimum concentrations for phase separation are approximately $3.0 \%(\mathrm{w} / \mathrm{w})$ gelatin and $0.1 \%(\mathrm{w} / \mathrm{w}) \mathrm{NaCMC}$. Furthermore, higher gelatin concentrations increased the minimum concentration of $\mathrm{NaCMC}$ necessary for macroscopic phase separation to occur. Soon after preparation, the solutions in the one-phase region appeared clear, and those in the two-phase region initially appeared turbid followed by macroscopic phase separation after a few hours. This behavior suggests a segregative phase separation, with the formation of two

Table 1. Intrinsic viscosity ([n]) and average viscosity molecular weight $\left(\mathrm{M}_{\mathrm{v}}\right)$ of gelatin and $\mathrm{NaCMC}$.

\begin{tabular}{lcc}
\hline \multicolumn{1}{c}{ Polymer } & {$[\mathbf{\eta}]\left(\mathbf{c m}^{\mathbf{3}} \mathbf{g}^{-1}\right)$} & $\mathbf{M}_{\mathbf{v}}(\mathbf{k D a})$ \\
\hline Gelatin & 58.86 & 85.48 \\
NaCMC & 394.05 & 89.38 \\
\hline
\end{tabular}

immiscible aqueous phases caused by repulsive interactions between the polymers ${ }^{[19]}$.

\subsubsection{Kinetic stability}

In the test of kinetic stability, it was observed that both the phase composition and the $\mathrm{pH}$ of the solution influence on biopolymer interactions and, hence, on the kinetics of phase separation. Figure 2 shows the SI of the emulsions prepared at $\mathrm{pH} 5.5,6.5$ and 7.5 over 3 days of storage at $45.0 \pm 0.1^{\circ} \mathrm{C}$. Because null values of SI for a long period of time are indicative of good stability of emulsions, it can be observed that, for all compositions tested, $\mathrm{pH} 5.5$ is the condition of lowest stability while $\mathrm{pH} 7.5$ is the condition of highest stability. At pH 7.5, macroscopic phase separation was not observed for 3 different compositions: $8 \%$ gelatin and $0.10 \% \mathrm{NaCMC}, 10 \%$ gelatin and $0.50 \% \mathrm{NaCMC}$ and $12 \%$ gelatin and $0.50 \% \mathrm{NaCMC}$. This result suggests that emulsions are more stable as $\mathrm{pH}$ moves from the isoelectric point of the protein due to an increase in repulsive interactions between the polymers. According to Dickinson ${ }^{[14]}$, the $\mathrm{pH}$ of the solutions controls the molecular charge distribution and the higher the polymer charge is, the lower the tendency of phase separation. A similar result was verified by Perrechil and Cunha ${ }^{[18]}$ who observed phase separation only at low $\mathrm{pH}$ values.

In addition to $\mathrm{pH}$, phase composition also influences the kinetics of phase separation. At pH 5.5, the emulsion with 6\% gelatin and $0.25 \% \mathrm{NaCMC}$ presented fastest phase separation, which was completed approximately $1 \mathrm{~h}$ after preparation, followed by emulsions with $8 \%$ gelatin and $0.1 \% \mathrm{NaCMC}$, $8 \%$ gelatin and $0.25 \% \mathrm{NaCMC}, 10 \%$ gelatin and $0.50 \%$ $\mathrm{NaCMC}$ and, lastly, $12 \%$ gelatin and $0.50 \% \mathrm{NaCMC}$, which started phase separation approximately $8 \mathrm{~h}$ after preparation. The same sequence of phase separation was observed in emulsions prepared at $\mathrm{pH} 6.5$ and 7.5.The increase in stability as a function of gelatin concentration can be explained by an increase in the viscosity of the continuous phase which limits the movement of the droplets and, therefore, their approximation and aggregation. Similar results were observed by Singh ${ }^{[19]}$ and Perrechil and Cunha ${ }^{[18]}$, where emulsions with higher polysaccharide concentrations were

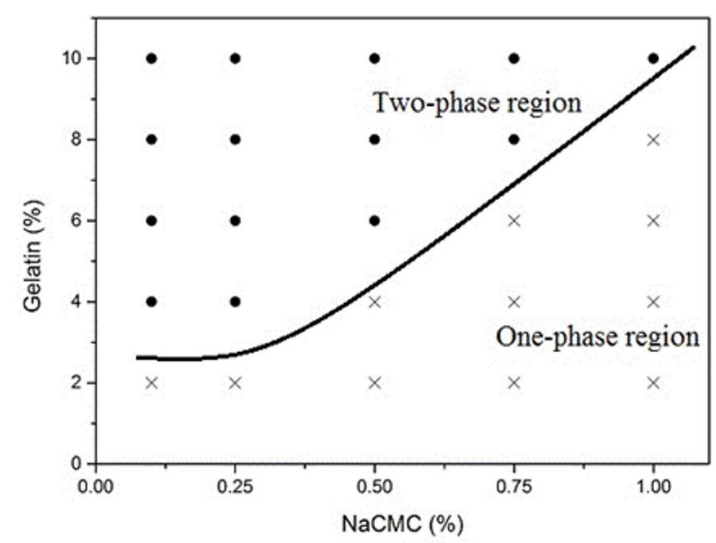

Figure 1. Phase diagram of gelatin-NaCMC system at $\mathrm{pH} 6.0$ and $45.0 \pm 0.1{ }^{\circ} \mathrm{C}$. The solid line represents the tendency of the binodal line. 


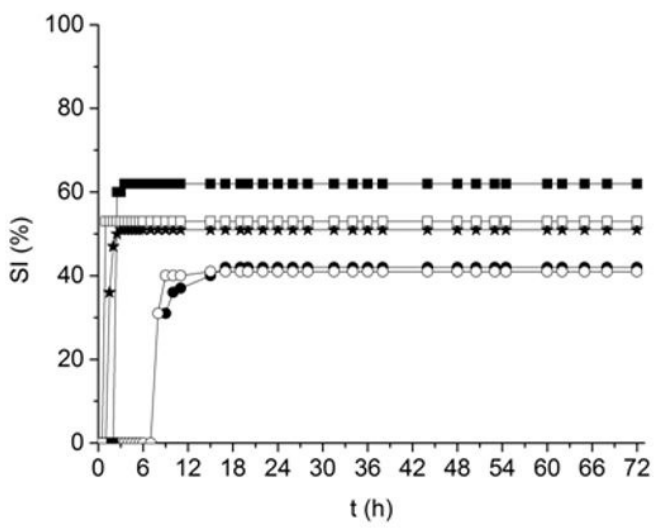

(a)

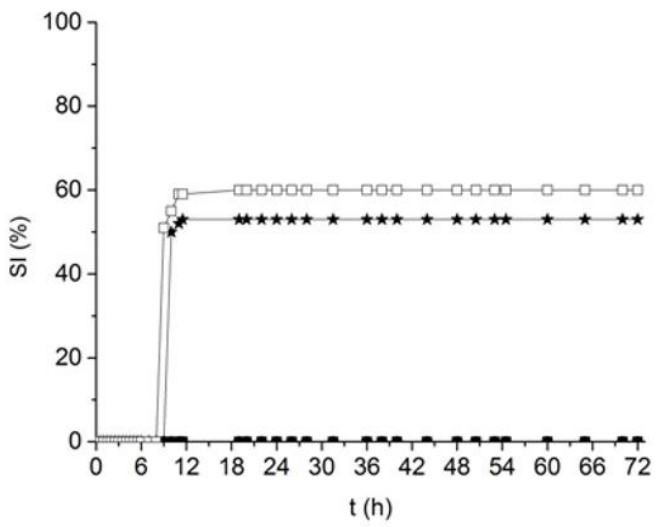

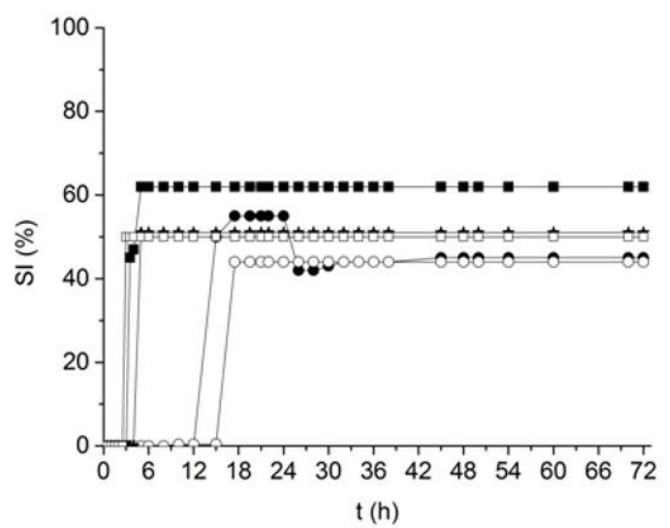

(b)

(c)

Figure 2. Separation index of $\mathrm{W} / \mathrm{W}$ emulsions at $\mathrm{pH}$ a) 5.5 ; b) 6.5 ; c) 7.5 , over 3 days at $45.0 \pm 0.1{ }^{\circ} \mathrm{C}(\bullet 12.0 \%$ gelatin, $0.50 \% \mathrm{NaCMC}$; $\circ 10.0 \%$ gelatin, $0.50 \% \mathrm{NaCMC}$, $\star 8.0 \%$ gelatin, $0.25 \% \mathrm{NaCMC} ; 8.0 \%$ gelatin, $0.10 \% \mathrm{NaCMC} ; \square 6.0 \%$ gelatin, $0.25 \% \mathrm{NaCMC}$ ).

more viscous and stable. Furthermore, the small difference in density between the two phases contributes to a slow phase separation. According to Dickinson ${ }^{[14]}$, a small difference in density between two aqueous phases implies a creaming rate up to 100 times lower than that of $\mathrm{O} / \mathrm{W}$ droplets of the same size. Another important observation was that the final SI of the emulsions is connected with the concentration of the disperse phase, with lower concentrations inducing higher SI values. Emulsions with $0.50 \%, 0.25 \%$ and $0.10 \%$ $\mathrm{NaCMC}$ presented separation indexes of approximately 41,52 and $62 \%$, respectively. The picture of the emulsions at different moments during the analysis is presented in Figure 3. After phase separation, a translucent upper layer and a turbid bottom layer were observed, indicating that the $\mathrm{NaCMC}$ droplets sedimented because they were denser and more opaque than the gelatin solution.

\subsection{Emulsion characterization}

\subsubsection{Dynamic superficial tension}

As shown in Figure 4, the gelatin-air and NaCMC-air systems presented a reduction in superficial tension with time until they reached equilibrium, indicating the migration of one or more components in solution to the interface ${ }^{[31]}$.

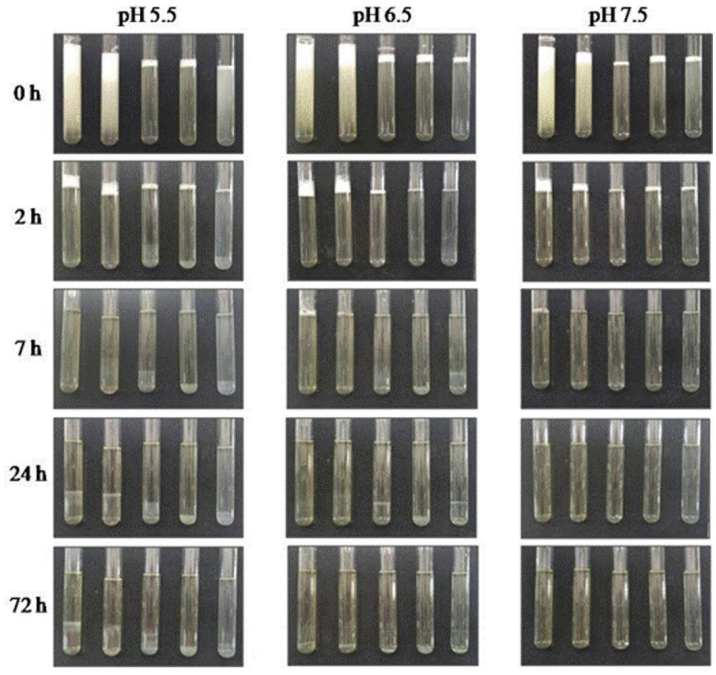

Figure 3. Pictures of the $\mathrm{W} / \mathrm{W}$ emulsions prepared at $\mathrm{pH} 5.5$, 6.5 and 7.5 , at different moments over 3 days of storage at $45.0 \pm 0.1^{\circ} \mathrm{C}$. From left to right, sample compositions corresponds to: $6 \%$ gelatin and $0.25 \% \mathrm{NaCMC} ; 8 \%$ gelatin and $0.10 \% \mathrm{NaCMC}$, $8 \%$ gelatin and $0.25 \% \mathrm{NaCMC}, 10 \%$ gelatin and $0.5 \% \mathrm{NaCMC}$ and $12 \%$ gelatin, $0.10 \% \mathrm{NaCMC}$. 
This behavior can be explained by the partially hydrophobic nature of proteins and polysaccharides or by the presence of impurities in solution active in the interface. The $\mathrm{NaCMC}$ solutions presented an initial superficial tension of approximately $65 \mathrm{mN} \cdot \mathrm{m}^{-1}$ followed by a fast reduction and a tendency for the rate of reduction to decrease until a steady state of approximately $50 \mathrm{mN} \cdot \mathrm{m}^{-1}$ was reached. The gelatin samples presented lower initial superficial tension, approximately $47 \mathrm{mN} . \mathrm{m}^{-1}$, because of larger amount of solutes in solution. Compared to that of the NaCMC solutions, a low rate of reduction was observed, which was related to the poor interfacial adsorption. In addition, a low tension variation and short time to reach the steady value could be observed.

The test of ANOVA showed that for NaCMC solutions, the concentration of the solutions does not have a significant influence $(p<0.05)$ on the equilibrium superficial tension, which may be related to the small difference in density between the solutions. However, it was verified that the gelatin concentration significantly influences the equilibrium superficial tension $(p<0.05)$.

\subsubsection{Droplet size and $\zeta$ potential}

The mean diameter $\left(\mathrm{d}_{\mathrm{m}}\right)$ of the emulsion droplets prepared at $\mathrm{pH} \mathrm{7.5,} \mathrm{the} \mathrm{polydispersity} \mathrm{index} \mathrm{(PDI)} \mathrm{and}$ the $\zeta$ potential, with the respective standard deviation are presented in Table 2.

These data show the formation of nanoemulsions, provided by the low interfacial tension that requires low energy to promote droplet breaking. The highly varied droplet sizes and the high PDI values show the formation of emulsions with broad size distribution. This result can be related to the

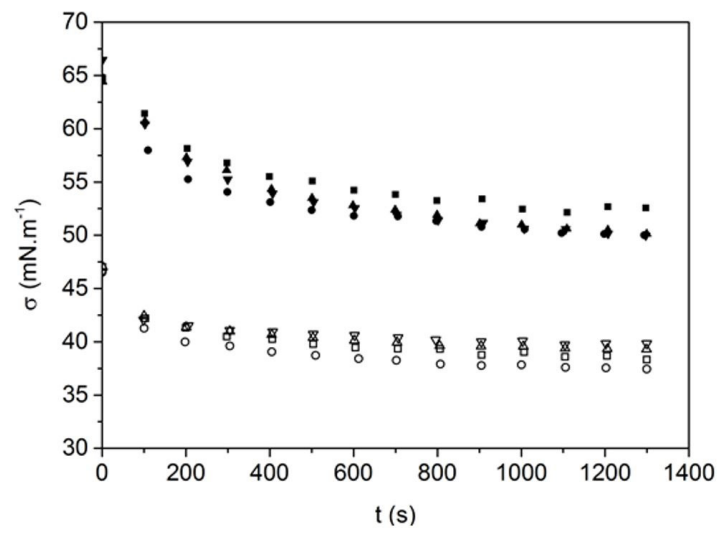

Figure 4. Superficial tension $(\sigma)$ with time $(t)$ of the polymer-air systems at $45.0 \pm 0.1{ }^{\circ} \mathrm{C}$ ( $\circ$ gelatin $6.0 \%$, $\square$ gelatin $8.0 \%$, $\Delta$ gelatin $10.0 \%, \nabla$ gelatin $12.0 \%$, $-\mathrm{NaCMC} 0.10 \%$, $\bullet \mathrm{NaCMC}$ $0.25 \%, \Delta \mathrm{NaCMC} 0.50 \%$ and $\mathbf{\nabla} \mathrm{NaCMC} 1.0 \%$ ). polydisperse characteristics of the polymers in addition to the occurrence of Ostwald Ripening, a common phenomenon in nanoemulsions, meaning that smaller particles submit themselves to the larger ones and start growing larger ${ }^{[32]}$.

The magnitude of the $\zeta$ potential is indicative of the stability of the colloidal system. According to Freitas ${ }^{[33]}$, a minimum $\zeta$ potential higher than $|60 \mathrm{mV}|$ is needed for excellent stability, and one higher than $|30 \mathrm{mV}|$ is needed for good physical stability. All the emulsions presented $\zeta<|20 \mathrm{mV}|$, indicating weak electrostatic repulsion between droplets. Thus, it may be assumed that any change in the physicochemical properties of the medium can cause instability in the system or that these emulsions would show phase separation if evaluated for longer periods. In addition, it can be considered that repulsive forces exceed attractive forces (van der Waals interactions), inhibiting the droplet approximation. The $\zeta$ potential value, however, is only one of many indications of emulsion stability and in some cases, this is not a relevant direct parameter to assess stability ${ }^{[34]}$.

\subsubsection{Viscosity}

The measurement of emulsion viscosity showed that this property is highly dependent on phase composition. The mean apparent viscosity of emulsions with $6 \%$ gelatin and $0.25 \% \mathrm{NaCMC}, 8 \%$ gelatin and $0.25 \% \mathrm{NaCMC}$ and $8 \%$ gelatin and $0.10 \% \mathrm{NaCMC}$, as well as their respective standard deviation, are presented in Table 3.

Emulsions with $10 \%$ gelatin and $0.50 \% \mathrm{NaCMC}$ and $12 \%$ gelatin and $0.50 \% \mathrm{NaCMC}$ presented different behaviors. In addition to the high viscosity, above 10 times the value of viscosity for the other compositions, it was observed that while shear is applied, the viscosity tends to increase and when shear is stopped, the emulsion reverts back to the original structure, a typical behavior of rheopectic fluids. By definition, rheopectic fluids show an increase in structure strength during the application of stress and consequent recovery of the structure and viscosity at the end of the stress period ${ }^{[35]}$. One of the main reasons for this behavior is that the shear increases both the frequency and the efficiency of collision between the droplets, which induces aggregation and, thus, increases the apparent viscosity ${ }^{[19]}$. Rheopexy in highly concentrated emulsions was discussed by Masalova et al. ${ }^{[36]}$, according to them, the restoration of the initial viscosity can be explained by elastic deformations of the droplets in the disperse phase.

\subsection{Effect of adding whey protein isolate on emulsion stability}

As shown in Figure 5, the WPI particles influenced the SI value and the rate of phase separation of emulsions prepared at $\mathrm{pH}$ 5.5. The extent of the effect was dependent

Table 2. Mean diameter $\left(\mathrm{d}_{\mathrm{m}}\right)$, polydispersity index (PDI) and $\zeta$ potential of the disperse phase of emulsions with different compositions at $\mathrm{pH} 7.5$.

\begin{tabular}{lccc}
\hline \multicolumn{1}{c}{ Composition } & $\mathbf{d}_{\mathbf{m}}(\mathbf{n m})$ & PDI & $\zeta(\mathbf{m V})$ \\
\hline $12 \%$ gelatin, $0.50 \% \mathrm{NaCMC}$ & $84.27 \pm 5.52$ & $0.95 \pm 0.04$ & $-17.00 \pm 1.16$ \\
$10 \%$ gelatin, $0.50 \% \mathrm{NaCMC}$ & $110.90 \pm 26.88$ & $0.70 \pm 0.12$ & $-18.00 \pm 1.57$ \\
$8 \%$ gelatin, $0.25 \% \mathrm{NaCMC}$ & $83.73 \pm 9.71$ & $1.00 \pm 0.00$ & $-15.94 \pm 1.03$ \\
$8 \%$ gelatin, $0.10 \% \mathrm{NaCMC}$ & $144.00 \pm 23.42$ & $0.76 \pm 0.33$ & $-10.96 \pm 0.19$ \\
$6 \%$ gelatin, $0.25 \% \mathrm{NaCMC}$ & $77.87 \pm 22.91$ & $0.84 \pm 0.20$ & $-16.44 \pm 1.97$ \\
\hline
\end{tabular}




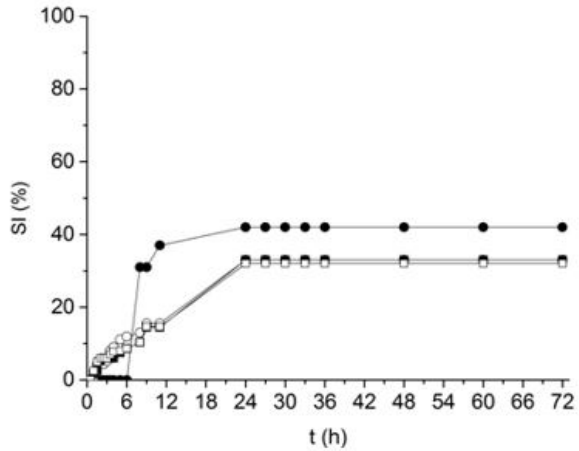

(a)

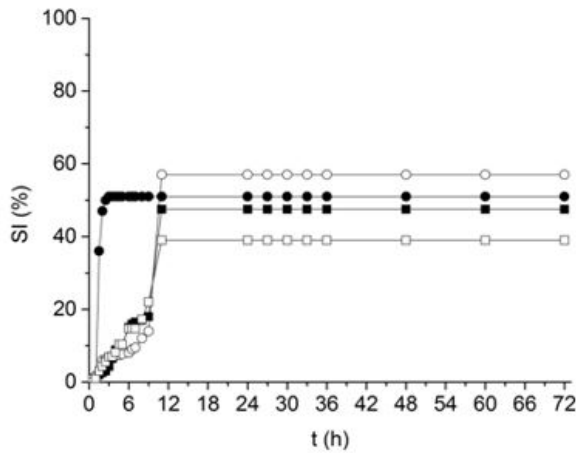

(c)

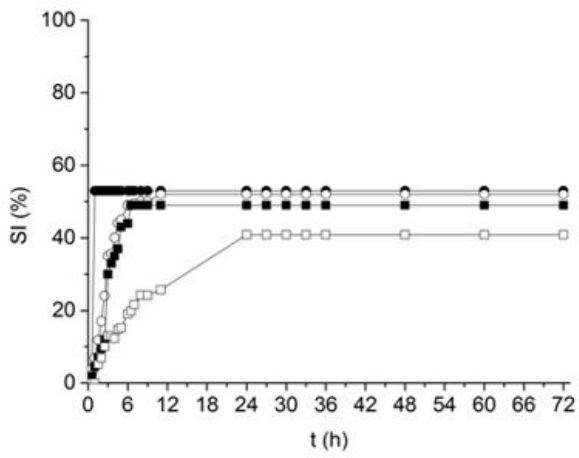

(e)

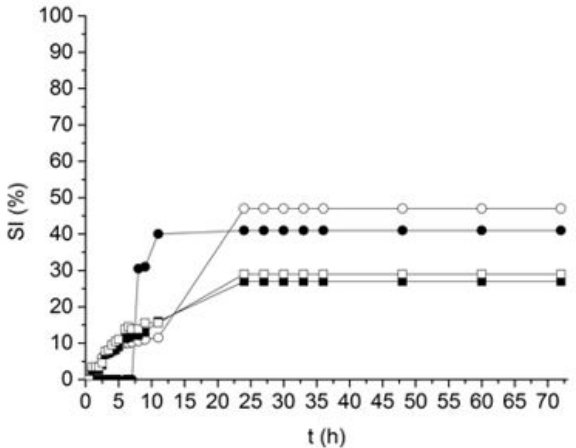

(b)

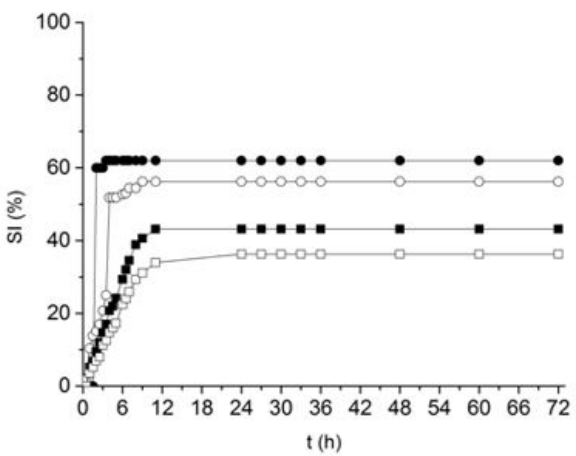

(d)

Figure 5. SI of emulsions with a) $12 \%$ gelatin and $0.50 \% \mathrm{NaCMC}$; b) $10 \%$ gelatin and $0.50 \% \mathrm{NaCMC}$; c) $8 \%$ gelatin and $0.25 \% \mathrm{NaCMC}$; d) $8 \%$ gelatin and $0.10 \% \mathrm{NaCMC}$; e) $6 \%$ gelatin and $0.25 \% \mathrm{NaCMC}$ over time with different concentration of WPI $(\bullet 0 \%$; $\circ 5 \%$; • $10 \%$; $\square 15 \%)$ at $\mathrm{pH} 5.5$.

Table 3. Mean apparent viscosity ( $\eta$ ) of the emulsions with different phase composition measured at different rotation speed $(v)$ at $45.0 \pm 0.5^{\circ} \mathrm{C}$ and $\mathrm{pH} 7.5$.

\begin{tabular}{ccc}
\hline Composition & $\boldsymbol{v}(\mathbf{r p m})$ & \multicolumn{1}{c}{$\boldsymbol{\eta}$ (mPa.s) } \\
\hline 8\% gelatin, $0.25 \% \mathrm{NaCMC}$ & 30 & $15.44 \pm 2.60$ \\
8\% gelatin, $0.10 \% \mathrm{NaCMC}$ & 60 & $8.00 \pm 0.41$ \\
$6 \%$ gelatin, $0.25 \% \mathrm{NaCMC}$ & 50 & $9.94 \pm 0.50$ \\
\hline
\end{tabular}

on the phase composition and the amount of protein added. The formation of a white and thick product in addition to high foaming was observed. Few minutes after the emulsion formation, it was possible to identify a thin clear upper layer, indicative of the beginning of the phase separation process, while emulsions without WPI remained homogeneous for approximately $1 \mathrm{~h}$. However, whereas emulsions without
WPI showed complete phase separation in no more than $6 \mathrm{~h}$ after formation, those with WPI particles showed complete phase separation only $24 \mathrm{~h}$ after formation, demonstrating that the protein particles were able to slow the rate of phase separation. Another relevant effect was the reduction of the SI compared to the formations without WPI. The emulsion with $8 \%$ gelatin and $0.1 \% \mathrm{NaCMC}$ presented this effect clearly: the SI, which was $62 \%$ before the addition of WPI, decreased to $36 \%$ after the addition of $15 \%$ WPI.

It was also observed that the addition of WPI influenced the kinetics of phase separation of the emulsions at almost all compositions, with the only exception being those with $12 \%$ gelatin and $0.50 \% \mathrm{NaCMC}$. The addition of $15 \%$ WPI caused a lower rate of phase separation and higher SI reduction. The application of the ANOVA test ensured that 
the addition of WPI had a significant influence $(p>0,05)$ on the SI value at any phase composition regardless of the amount of protein added.

The use of WPI microgel particles as stabilizing agents in $\mathrm{O} / \mathrm{W}$ emulsions is extensively well known ${ }^{[37-39]}$ however, the use of these particles in stabilizing $\mathrm{W} / \mathrm{W}$ emulsions is very recent and still question still remain about the best conditions for using them. This is because the heat treatment induces the aggregation of protein molecules in solution, and stable suspensions of protein-based soft hydrogels are obtained. These hydrogel particles could adsorb on the interface much more strongly than could native untreated protein. As a result, remarkable stable water-in-water emulsions could be obtained because of the Pickering mechanism ${ }^{[6,12]}$. Recent discoveries have revealed that the Pickering effect is efficient only when the particles undergo an aggregation process at the interface ${ }^{[10,12]}$ and when the particle is preferably solvated by the continuous phase ${ }^{[14]}$. According to Dickinson ${ }^{[14]}$, one significant disadvantage of WPI microgel as W/W emulsion stabilizers is the tendency of the particles to flocculate in the vicinity of the isoeletric point of the protein $(\mathrm{pI} \sim 5)$ and thus, it is expected that the particles might be more efficient on stabilizing emulsions prepared at $\mathrm{pH}>5.5$. Although the addition of WPI particles retarded the phase separation, the stability time of the emulsions prepared at $\mathrm{pH} 7.5$ could not be exceeded without the addition of particles.

\section{Conclusions}

Under specific conditions of $\mathrm{pH}$ and phase composition, it is possible to produce stable $\mathrm{W} / \mathrm{W}$ emulsions for at least 3 days of storage without the addition of stabilizing agents. Emulsions prepared at the $\mathrm{pH}$ furthest from the isoelectric point of gelatin and with high protein concentration presented the best stability. WPI particles added to emulsions at $\mathrm{pH} 5.5$ showed the ability to reduce the phase separation speed and $15 \%$ WPI showed this effect clearly. Emulsions at $\mathrm{pH} 5.5$ with WPI remained less stable than those prepared at $\mathrm{pH} 7.5$ and $12 \%$ gelatin without WPI. Reducing the rate of phase separation opens new possibilities for research using particles to stabilize emulsions with practical applications in the formulation of functional food and in the encapsulation of bioactive components.

\section{Acknowledgements}

The authors thank to Conselho Nacional de Desenvolvimento Científico e Tecnológico (CNPq), Fundação de Amparo à Pesquisa do Estado do Rio de Janeiro (FAPERJ) and Coordenação de Aperfeiçoamento de Pessoal de Nível Superior (CAPES) (Finance code 001) for financial support.

\section{References}

1. Zhang, J., Hwang, J., Antonietti, M., \& Schmidt, B. V. (2018). Water-in-water Pickering emulsion stabilized by polydopamine particles and cross-linking. Biomacromolecules. http://dx.doi. org/10.1021/acs.biomac.8b01301. PMid:30395449.

2. Chen, J.-F., Guo, J., Zhang, T., Wan, Z.-L., Yang, J., \& Yang, X.-Q. (2018). Slowing the starch digestion by structural modification through preparing zein/pectin particle stabilized water-in-water emulsion. Journal of Agricultural and Food Chemistry, 66(16), 4200-4207. http://dx.doi.org/10.1021/acs. jafc.7b05501. PMid:29624058.

3. Beldengrün, Y., Aragon, J., Prazeres, S. F., Montalvo, G., Miras, J., \& Esquena, J. (2018). Gelatin/maltodextrin water-in-water $(\mathrm{w} / \mathrm{w})$ emulsions for the preparation of cross-linked enzymeloaded microgels. Langmuir, 34(33), 9731-9743. http://dx.doi. org/10.1021/acs.langmuir.8b01599. PMid:29954182.

4. Dewey, D. C., Strulson, C. A., Cacace, D. N., Bevilacqua, P. C., $\&$ Keating, C. D. (2014). Bioreactor droplets from liposomestabilized all-aqueous emulsions. Nature Communications, 5(1), 1-9. http://dx.doi.org/10.1038/ncomms5670. PMid:25140538.

5. Song, Y., Shimanovich, U., Michaels, T. C. T., Ma, Q., Li, J., Knowles, T. P. J., \& Shum, H. C. (2016). Fabrication of fibrillosomes from droplets stabilized by protein nanofibrils at all-aqueous interfaces. Nature Communications, 7(1), 12934. http://dx.doi.org/10.1038/ncomms12934. PMid:27725629.

6. Esquena, J. (2016). Water-in-water (W/W) emulsions. Current Opinion in Colloid \& Interface Science, 25, 109-119. http:// dx.doi.org/10.1016/j.cocis.2016.09.010.

7. Poortinga, A. T. (2008). Microcapsules from self-assembled colloidal particles using aqueous phase-separated polymer solutions. Langmuir, 24(5), 1644-1647. http://dx.doi.org/10.1021/ la703441e. PMid: 18220438.

8. Chatsisvili, N., Philipse, A. P., Loppinet, B., \& Tromp, R. H. (2017). Colloidal zein particles at water-water interfaces. Food Hydrocolloids, 65, 17-23. http://dx.doi.org/10.1016/j. foodhyd.2016.10.036.

9. Douliez, J. P., Martin, N., Beneyton, T., Eloi, J. C., Chapel, J. P., Navailles, L., Baret, J. C., Mann, S., \& Béven, L. (2018). Preparation of swellable hydrogel-containing colloidosomes from aqueous two-phase Pickering emulsion droplets. Angewandte Chemie, 57(26), 7906-7910. http://dx.doi.org/10.1002/ ange.201802929. PMid:29683257.

10. Murray, B. S., \& Phisarnchananan, N. (2016). Whey protein microgel particles as stabilizers of waxy corn starch + locust bean gum water-in-water emulsions. Food Hydrocolloids, 56, 161-169. http://dx.doi.org/10.1016/j.foodhyd.2015.11.032.

11. Freitas, R. A., Nicolai, T., Chassenieux, C., \& Benyahia, L. (2016). Stabilization of water-in-water emulsions by polysaccharide-coated protein particles. Langmuir, 32(5), 1227-1232. http://dx.doi.org/10.1021/acs.langmuir.5b03761. PMid:26757399.

12. Nguyen, B. T., Nicolai, T., \& Benyahia, L. (2013). Stabilization of water-in-water emulsions by addition of protein particles. Langmuir, 29(34), 10658-10664. http://dx.doi.org/10.1021/ la402131e. PMid:23895275.

13. Nicolai, T., \& Murray, B. (2017). Particle stabilized water in water emulsions. Food Hydrocolloids, 68, 157-163. http:// dx.doi.org/10.1016/j.foodhyd.2016.08.036.

14. Dickinson, E. (2018). Particle-based stabilization of water-inwater emulsions containing mixed biopolymers. Trends in Food Science \& Technology. 83:31-40. http://dx.doi.org/10.1016/j. tifs.2018.11.004

15. Huei, C. R., \& Hwa, H. D. (1996). Effect of molecular weight of chitosan with the same degree of deacetylation on the thermal, mechanical, and permeability properties of the prepared membrane. Carbohydrate Polymers, 29(4), 353-358. http://dx.doi.org/10.1016/S0144-8617(96)00007-0.

16. Riihimaki, T. A. (1973). Rheological studies of the kinetics of gelation (Master's dissertation). University of Massachusets, Massachusets.

17. Kurata, M. (1999). Viscosity-molecular weight relationships and unperturbed dimensions of linear chain molecules. In: J. Brandrup, E. H. Immergut, \& E. A. Grulke (Eds.), Polymer 
handbook (Vol. 7). New York: John Wiley \& Sons. http:// dx.doi.org/10.1002/0471532053.bra049.

18. Perrechil, F. A., \& Cunha, R. L. (2012). Development of multiple emulsions based on the repulsive interaction between sodium caseinate and LBG. Food Hydrocolloids, 26(1), 126134. http://dx.doi.org/10.1016/j.foodhyd.2011.04.017.

19. Singh, P., Medronho, B., Miguel, M. G., \& Esquena, J. (2018). On the encapsulation and viability of probiotic bacteria in edible carboxymethylcellulose-gelatin water-in-water emulsions. Food Hydrocolloids, 75, 41-50. http://dx.doi.org/10.1016/j. foodhyd.2017.09.014.

20. Mcclements, D. J. (2005). Food Emulsions: Principles, practices, and techniques. Florida: CRC Press.

21. Ushikubo, F. Y., \& Cunha, R. L. (2014). Stability mechanisms of liquid water-in-oil emulsions. Food Hydrocolloids, 34, 145-153. http://dx.doi.org/10.1016/j.foodhyd.2012.11.016.

22. Gomes, A., Costa, A. L. R., Assis Perrechil, F., \& Cunha, R. L. (2016). Role of the phases composition on the incorporation of gallic acid in $\mathrm{O} / \mathrm{W}$ and W/O emulsions. Journal of Food Engineering, 168, 205-214. http://dx.doi.org/10.1016/j. jfoodeng.2015.07.041.

23. Masuelli, M. A., \& Sansone, M. G. (2012). Hydrodynamic properties of gelatin-studies from intrinsic viscosity measurements. In: J. Verbeek. Products and pplications of biopolymers (pp. 85-116). Argentina: InTech.

24. Ledward, D. A. (2000). Gelatin. In G. O. Phillips \& P. A. Williams, Handbook of hydrocolloids (pp. 67-86). United States of America: CRC Press.

25. Masuelli, M. A. (2014). Mark-Houwink parameters for aqueoussoluble polymers and biopolymers at various temperatures. Journal of Polymer and Biopolymer Physics Chemistry, 2(2), 37-43. http://dx.doi.org/10.12691/jpbpc-2-2-2.

26. Vázquez, M. J., Gómez-Amoza, J., Martínez-Pachelo, R., Souto, C., \& Concheiro, A. (1995). Relationships between drug dissolution profile and gelling agent viscosity in tablets prepared with hydroxypropylmethylcellulose (HPMC) and sodium carboxymethylcellulose (NaCMC) mixtures. Drug Development and Industrial Pharmacy, 21(16), 1859-1874. http://dx.doi.org/10.3109/03639049509070862.

27. Sharma, R., Das, B., Nandi, P., \& Das, C. (2010). Viscosity of sodium carboxymethylcellulose in ethylene glycol-water mixed solvent media: separation of the influences of polyion conformation and electrostatic interactions on the reduced viscosity. Journal of Polymer Science. Part B, Polymer Physics, 48(11), 1196-1202. http://dx.doi.org/10.1002/polb.22009.

28. Gómez-Díaz, D., \& Navaza, J. M. (2003). Rheology of aqueous solutions of food additives: effect of concentration, temperature and blending. Journal of Food Engineering, 56(4), 387-392. http://dx.doi.org/10.1016/S0260-8774(02)00211-X.

29. Rinaudo, M., Danhelka, J., \& Milas, M. (1993). A new approach to characterizing carboxymethylcelluloses by size exclusion chromatography. Carbohydrate Polymers, 21(1), 1-5. http:// dx.doi.org/10.1016/0144-8617(93)90109-H.

30. Caraschi, J., \& Campana, S. P. (1999). Influência do grau de substituição e da distribuição de substituintes sobre as propriedades de equilíbrio de carboximetilcelulose em solução aquosa. Polimeros: Ciência e Tecnologia, 9(2), 70-77. http:// dx.doi.org/10.1590/S0104-14281999000200015.

31. Andreas, J. M., Hauser, E. A., \& Tucker, W. B. (1938). Boundary tension by pendant drops. Journal of Physical Chemistry, 42(8), 1001-1019. http://dx.doi.org/10.1021/j100903a002.

32. Mason, T. G., Wilking, J. N., Meleson, K., Chang, C. B., \& Graves, S. M. (2006). Nanoemulsions: Formation, structure, and physical properties. Journal of Physics Condensed Matter, 18(41), R635-R666. http://dx.doi.org/10.1088/0953-8984/18/41/ R01.

33. Freitas, C., \& Müller, R. H. (1998). Effect of light and temperature on zeta potential and physical stability in solid lipid nanoparticle (SLN ${ }^{\mathrm{TM}}$ ) dispersions. International Journal of Pharmaceutics, 168(2), 221-229. http://dx.doi.org/10.1016/ S0378-5173(98)00092-1.

34. Roland, I., Piel, G., Delattre, L., \& Evrard, B. (2003). Systematic characterization of oil-in-water emulsions for formulation design. International Journal of Pharmaceutics, 263(1-2), 85-94. http://dx.doi.org/10.1016/S0378-5173(03)00364-8. PMid:12954183.

35. Gabas, A. L., Menezes, R. S., \& Telis-Romero, J. (2012). Reologia na Indústria de Biocombustiveis. Brazil: Indi.

36. Masalova, I., Taylor, M., Kharatiyan, E., \& Malkin, A. Y. (2005). Rheopexy in highly concentrated emulsions. Journal of Rheology, 49(4), 839-849. http://dx.doi.org/10.1122/1.1940641.

37. Destribats, M., Rouvet, M., Gehin-Delval, C., Schmitt, C., \& Binks, B. P. (2014). Emulsions stabilised by whey protein microgel particles: towards food-grade Pickering emulsions. Soft Matter, 10(36), 6941-6954. http://dx.doi.org/10.1039/ C4SM00179F. PMid:24675994.

38. Wu, J., Shi, M., Li, W., Zhao, L., Wang, Z., Yan, X., Norde, W., \& Li, W. (2015). Pickering emulsions stabilized by whey protein nanoparticles prepared by thermal cross-linking. Colloids and Surfaces. B, Biointerfaces, 127, 96-104. http:// dx.doi.org/10.1016/j.colsurfb.2015.01.029. PMid:25660092.

39. Sarkar, A., Murray, B., Holmes, M., Ettelaie, R., Abdalla, A., \& Yang, X. (2016). In vitro digestion of Pickering emulsions stabilized by soft whey protein microgel particles: Influence of thermal treatment. Soft Matter, 12(15), 3558-3569. http:// dx.doi.org/10.1039/C5SM02998H. PMid:26959339.

Received: May 03, 2019 Revised: Sept. 04, 2019 Accepted: Oct. 19, 2019 